\title{
BMJ Open Association of intimate partner violence during pregnancy and birth weight among term births: a cross-sectional study in Kaduna, Northwestern Nigeria
}

\author{
Musa Abubakar Kana (D) , ${ }^{1,2,3}$ Halima Safiyan, ${ }^{4}$ Hauwau Evelyn Yusuf, ${ }^{5}$ \\ Abu Saleh Mohammad Musa, ${ }^{6}$ Marie Richards-Barber, ${ }^{7}$ Quaker E Harmon, ${ }^{1}$ \\ Stephanie J London ${ }^{1}$
}

To cite: Kana MA, Safiyan $\mathrm{H}$, Yusuf HE, et al. Association of intimate partner violence during pregnancy and birth weight among term births: a cross-sectional study in Kaduna, Northwestern Nigeria. BMJ Open 2020;10:e036320. doi:10.1136/ bmjopen-2019-036320

- Prepublication history and additional materials for this paper are available online. To view these files, please visit the journal online (http://dx.doi. org/10.1136/bmjopen-2019036320).

Received 11 December 2019 Revised 06 October 2020 Accepted 06 November 2020

Check for updates

(c) Author(s) (or their employer(s)) 2020. Re-use permitted under CC BY-NC. No commercial re-use. See rights and permissions. Published by BMJ.

For numbered affiliations see end of article.

Correspondence to Dr Musa Abubakar Kana; musakana77@yahoo.com

\section{ABSTRACT}

Objective To determine the association of prenatal exposure to intimate partner violence (IPV) with birth weight as a continuous variable among term births in a Nigerian population.

Design Cross-sectional study.

Setting Mother-child pairs recruited when their newborns were brought for BCG or other vaccines shortly after birth at the Child Welfare Clinic of Barau Dikko Teaching Hospital, Kaduna, Nigeria.

Participants 293 women with term birth infants. Main exposure and outcome measures Emotional, physical and sexual IPV were measured postnatally by interview using the Conflict Tactics Scale. Birth weight in grams was the main outcome measure. Linear regression, with adjustment for covariates, was used to estimate associations between birth weight and exposure to the presence, and frequency, of IPV.

Results Sixty-seven per cent of mothers experienced at least one of the three forms of IPV during pregnancy. Relative to the $33 \%$ of women with no prenatal exposure to any form of IPV, we observed a reduction in birth weight of $94 \mathrm{~g}(95 \% \mathrm{Cl}:-202$ to 15$)$ for prenatal exposure to emotional IPV, $162 \mathrm{~g}(95 \% \mathrm{Cl}-267$ to -58$)$ for physical IPV and $139 \mathrm{~g}(95 \% \mathrm{Cl}-248$ to -30$)$ for sexual IPV. The combination of all three forms of IPV was associated with a $223 \mathrm{~g}$ reduction in birth weight $(95 \% \mathrm{Cl}-368$ to -77$)$. Increasing occurrences of each of the three types of IPV were associated with greater reductions in birth weight. For physical IPV, relative to no exposure to any form of IPV, birth weight was lower by $112 \mathrm{~g}(95 \% \mathrm{Cl}-219$ to -4$)$ with $1-5$ instances and $380 \mathrm{~g}(95 \% \mathrm{Cl}-553$ to -206$)$ for $>5$ instances over the pregnancy.

Conclusions Maternal exposure to IPV was associated with shifting of the birth weight distribution among term newborns. A dose-response relationship was observed between frequency of IPV and birth weight.

\section{BACKGROUND}

Intimate partner violence (IPV) during pregnancy is a global public health problem for its consequences on maternal and fetal health. ${ }^{1-3}$ IPV is the foremost cause of reported trauma during pregnancy and the prevalence varies
Strengths and limitations of this study

- Evaluation of impact of different forms of intimate partner violence (IPV) (emotional, physical, sexual) and their combined effect on birth weight in Nigerian women.

- The use of Conflict Tactics Scale for measuring the prevalence of forms of IPV, and their frequencies, which enabled the estimation of dose-response relationships.

- We sought replication of our key findings in a larger prospective birth cohort in another sub-Saharan African country: Tanzania.

- Assessment of prenatal IPV after delivery raises concern about potential recall bias.

- Possibility of unmeasured confounding for factors such as hypertension, maternal smoking and alcohol ingestion during pregnancy.

between and within countries. ${ }^{45}$ Individuallevel demographic, psychocognitive, and sociocultural factors of a woman and her intimate partner primarily determine IPV. ${ }^{6}$ Prenatal IPV has been related to adverse birth outcomes including low birth weight (LBW) ${ }^{7-9}$ The mechanisms of how IPV exposure during pregnancy might impact birth outcomes include direct and indirect biological effects on fetal growth. ${ }^{10}$ Prenatal IPV is considered a potentially modifiable risk factor for the prevention of LBW. ${ }^{1112}$

Using a variety of IPV screening tools, which vary in psychometric properties and suitability for assessing the different forms of IPV and their frequencies, ${ }^{13-16}$ prenatal exposure to emotional, physical or sexual forms of IPV, singly, or in combination, has been shown to be associated with LBW as a binary outcome. ${ }^{12}$ Although numerous studies have examined the association of physical IPV and LBW, ${ }^{1}$ few have focused on the effects 
of emotional or sexual IPV. Identifying the differential effects of different forms of IPV may have implications for developing interventions.

Prior studies have primarily used categorical LBW, as opposed to continuous birth weight, which will not detect shifts of birth weight distribution across the entire range. In addition, because birth weight is highly influenced by gestational age, ${ }^{17} 18$ studies limited to term infants can estimate unbiased associations with birth weight independent of gestational age. Importantly, the association of prenatal IPV and birth weight as a continuous variable among term births has not been extensively studied in sub-Saharan Africa. ${ }^{1}{ }^{13}{ }^{19-26}$ Furthermore, evidence synthesis has shown that few of the prior studies explored a potential dose-response relationship of prenatal IPV exposure and birth weight among term birth infants. ${ }^{1327}$

Although the prevalence of IPV among pregnant women in sub-Saharan Africa is one of the highest reported globally, there are scant contemporary epidemiological studies about its effect on birth weight in the region. ${ }^{13} 1920252628$ Nigeria is Africa's most populous nation and among the five countries where most of the small-for-gestational-age infants are born in the world. ${ }^{29}$ Investigating the effect of potentially modifiable risk factors like IPV exposure during pregnancy would be needed for designing evidence-based interventions. Therefore, in this study, we aimed to determine the association of prenatal exposure to IPV with birth weight, analysed as a continuous variable, among term births in a Nigerian population. We considered both the presence and frequency of IPV exposure.

\section{METHODS}

\section{Study setting and population}

This cross-sectional study was conducted at the Child Welfare Clinic of Barau Dikko Teaching Hospital, Kaduna (Kaduna State, Northwestern Nigeria). The catchment area of this hospital is the entire city of Kaduna, the fourth largest in Nigeria based on a population of 1.6 million. ${ }^{30}$ We collected data for this study using the electronic data capture platform, Research Electronic Data Capture. Participants of this study were selected from a larger population that has been previously described (online supplemental file 1-participant selection flowchart). ${ }^{31}$ This larger population included all women who brought their newborns to the study site for BCG vaccination and growth monitoring within the first week of life over the period of January 2017-April 2019. The participant recruitment for the IPV study occurred in OctoberDecember 2018 and targeted all mothers whose infants were 14 weeks of age or less at the time of the clinic visit. We limited enrolment to this 14-week window because we were asking retrospectively about IPV exposure during pregnancy. This recruitment strategy also allowed inclusion of mothers who delivered at home, to improve the study's generalisability. A total of 328 mother-child pairs met the inclusion criteria of providing informed consent to participate and having birth weight measured at birth or within 48 hours of delivery and entered on the child health card (online supplemental file 2). Multiple births were excluded because they have a higher risk of preterm birth and LBW. Two trained research assistants collected information regarding IPV using the Conflict Tactics Scale (CTS) by conducting face-to-face interviews after the BCG immunisation in a secluded space situated away from the Child Welfare Clinic. ${ }^{32}$ The CTS has questions enquiring about the presence and frequency of specific acts to measure different forms of IPV. ${ }^{33}$ Additionally, the CTS has cross-cultural reliability and validity as well as high sensitivity and specificity for detecting violence against pregnant women. ${ }^{14}{ }^{15}$ All the interview sessions were done in either English or Hausa, depending on the participant's preference, with each interview, including informed consent, lasting an average of $25 \mathrm{~min}$ for approximately 7-10 women per day.

\section{Exposure and outcome measurements \\ Exposure variable}

The CTS evaluates three domains of IPV: emotional violence (three questions), physical violence (seven questions) and sexual violence (three questions) by asking the woman about whether her husband/partner committed specific acts that constitute IPV. A yes answer to one or more of items within a domain is evidence of having experienced that specific form of IPV (online supplemental table S1). We used the generally accepted standard for CTS scoring described in the CTS manual. ${ }^{33}$ Binary variables were created to indicate exposure or not, during the pregnancy, to each type of IPV: emotional, physical or sexual. The following variables were created to assess exposure to combined forms of IPV: either emotional or physical, either emotional or sexual, either physical or sexual, or a combination of all three forms of IPV. For each of these combined variables, the reference category was no exposure to any form of IPV during the pregnancy.

The CTS also elicits the frequency of each type of IPV in categories ranging from once to more than 20 times across pregnancy (online supplemental file 3 ) ${ }^{33}$ In order to use the same categories across the three types of IPV, and to avoid sparse frequencies in some categories, we collapsed the categories on the CTS into three: no exposure, one to five times during the pregnancy or more than five times.

\section{Outcome variables}

Birth weight (in grams) was recorded as a continuous variable on the child health (immunisation and growth monitoring) card. Trained nurses/midwives measured the birth weight using a digital scale at birth for infants delivered in the health facility or within 48 hours, during the BCG immunisation visit, for those delivered at home. Birth weight was measured without clothing. Scales were calibrated using a standard weight to ensure accuracy and comparability. We restricted the analysis to term births ( $\geq 37$ completed weeks) as birth weight is highly influenced 
by gestational age. ${ }^{17}$ The algorithm for identifying term births was based on self-report of the last menstrual period (LMP). We had imprecision in the estimation of gestational age because some women did not remember their LMP and women in our population generally report their gestational length in whole completed months rather than in weeks. There are approximately 4.25 weeks in a month and through the conversion of months to weeks for data entry, 9-month pregnancies were recorded as 38.25 weeks ( 9 months times 4.25 weeks).

\section{Covariates}

We obtained covariates from the structured questionnaire administered to all participants (online supplemental file 3) ${ }^{34}$ We evaluated established risk factors for LBW in the literature for association with IPV in our data. ${ }^{6} 1635$ These included maternal age recorded continuously but classified as $<20,20-34$ and $\geq 35$ years, educational level (none, primary, secondary and tertiary), employment status (employed or not employed) and parity (primiparae or multiparae). Other covariates considered were the intimate partner's educational level (none, primary, secondary and tertiary), use of alcohol or illicit drugs, and household poverty probability level categorised as low, intermediate or high.

\section{Household poverty probability level}

The participant's household socioeconomic level was derived from the Poverty Probability Index (PPI). ${ }^{36}$ The PPI consists of 10 structured questions included in the study questionnaire (online supplemental file 3). Each question has categories that are scored and these scores are summed across all questions for each participant household to obtain a total household PPI score. The total scores ranged from 0 to 100 and we used the Nigerian-specific look-up table (online supplemental file 4) to convert the total score to a poverty likelihood score (percentiles). We summarised the poverty likelihood scores (probability level) into quartiles and merged the middle quartiles to create three categories: low $(\leq 25 \%)$, intermediate $(26 \%-75 \%)$ and high $(>75 \%)$.

\section{Statistical analysis}

A total of 293 term infants were included in all analyses. We compared maternal, intimate partner and infant characteristics by maternal exposure to any prenatal IPV (yes or no). $\mathrm{X}^{2}$ and Fisher's exact tests were used to compare discrete variables, while analysis of variance was used for continuous variables. Linear regression was used to assess the relationship of prenatal exposure to IPV with birth weight among term births. We conducted this analysis with the various forms of IPV expressed as binary exposures (yes or no) as well as categories of IPV frequency (none, 1-5 times and $>5$ times during pregnancy) to characterise the dose-response association. We tested for a dose-response relationship across the three frequency exposure categories using an ordinal term, scored as 0 , 1 or 2 , and reported the $\mathrm{p}$ value for this ordinal test for trend. The estimated $\beta$ coefficients correspond to the difference in birth weight (in grams) for the relevant exposure to IPV. We evaluated covariates described above that were related to birth weight in the literature and retained those in adjusted models that were associated, at $p$ value of $<0.05$, with any of the three IPV variables. These were maternal age, parity, education and householdpredicted poverty level.

Because our data on IPV were collected after birth, we attempted to replicate our results using a publicly available dataset from a prospective study in Tanzania in which information about IPV was collected during pregnancy. This study of 1112 mother-newborn pairs previously reported the association of prenatal IPV with gestational age and birth weight as binary outcomes (preterm birth and LBW).${ }^{19}$ The women were recruited before 24 weeks' gestation when ultrasound was performed to estimate gestational age, evaluated for exposure to IPV during pregnancy at 34 weeks' gestation and birth weight was measured, using a calibrated digital scale, either in the hospital immediately after delivery or within 48 hours after delivery for women who delivered at home. Nearly all women $(98.8 \%)$ delivered in a health facility. Exposure to IPV was assessed using the questionnaire employed in the WHO Multi-Country Study on Women and Domestic Violence against Women. ${ }^{5}$ The questionnaire was built on the design of the CTS, in that women were asked questions about their experience of specific acts of emotional, physical and sexual violence during pregnancy by the intimate partner. In the Tanzanian data, we estimated the association between prenatal IPV exposure and birth weight as a continuous variable among 1024 term births with adjustment for maternal age, parity, education, height and smoking (daily, occasionally or not at all).

We set the threshold of statistical significance for all analyses at 0.05 . SPSS V.23 was used to perform all analyses. A completed copy of the Strengthening the Reporting of Observational Studies in Epidemiology checklist for cross-sectional studies is included as online supplemental file 5 .

\section{RESULTS}

Sociodemographic, intimate partner and infant characteristics by maternal exposure to any prenatal IPV among term births

Maternal age was not significantly different for those exposed to prenatal IPV (28.8 \pm 5.9 years) compared with unexposed (29.2 \pm 5.7 years). IPV exposed and unexposed women were comparable in marital status, parity, employment status and educational level of the intimate partner (table 1). The two IPV exposure groups differed by maternal education, household poverty probability level, substance abuse by the intimate partner and infant birth outcomes. The proportion of tertiary-educated women was lower among the IPV exposed (35\%) than the unexposed $(50 \%)$. The prevalence of women residing in households with intermediate-high poverty probability level was greater in the IPV exposed (65\%) compared 
Table 1 Maternal sociodemographic, intimate partner and infant characteristics by maternal exposure to any prenatal intimate partner violence among 293 term births

\begin{tabular}{|c|c|c|c|}
\hline \multirow[b]{2}{*}{ Variable n (\%) } & \multicolumn{2}{|c|}{$\begin{array}{l}\text { Exposure to prenatal } \\
\text { intimate partner violence }\end{array}$} & \multirow{2}{*}{$\begin{array}{l}P \\
\text { value }\end{array}$} \\
\hline & Yes $(n=195)$ & No $(n=98)$ & \\
\hline Maternal age, mean $\pm S D$ & $28.8 \pm 5.9$ & $29.2 \pm 5.7$ & 0.58 \\
\hline$<20$ years & $8(4.1)$ & $3(3.1)$ & 0.85 \\
\hline 20-34 years & $152(77.9)$ & $79(80.6)$ & \\
\hline$\geq 35$ years & $35(17.9)$ & $16(16.3)$ & \\
\hline \multicolumn{4}{|l|}{ Current marital status* } \\
\hline Married & $190(97.4)$ & $98(100)$ & \\
\hline Unmarried & $5(2.6)$ & $0(0.0)$ & \\
\hline \multicolumn{4}{|l|}{ Parity } \\
\hline Primiparae & $45(23.1)$ & $30(30.6)$ & 0.16 \\
\hline Multiparae & $150(76.9)$ & $68(69.4)$ & \\
\hline \multicolumn{4}{|l|}{ Educational level } \\
\hline No tertiary education & $126(64.6)$ & $49(50.0)$ & 0.02 \\
\hline Tertiary education & $69(35.4)$ & $49(50.0)$ & \\
\hline \multicolumn{4}{|l|}{ Maternal employment status* } \\
\hline Unemployed & $72(37.1)$ & $35(35.7)$ & 0.89 \\
\hline Employed & $122(62.9)$ & $63(64.3)$ & \\
\hline \multicolumn{4}{|c|}{ Household poverty probability level } \\
\hline Low $(\leq 25 \%)$ & $69(35.4)$ & $51(52.0)$ & 0.02 \\
\hline Intermediate (26\%-75\%) & $110(56.4)$ & $43(43.9)$ & \\
\hline High (>75\%) & $16(8.2)$ & $4(4.1)$ & \\
\hline \multicolumn{4}{|c|}{ Educational level of intimate partner } \\
\hline No tertiary education & $88(45.4)$ & $34(34.7)$ & 0.1 \\
\hline Tertiary education & $106(54.6)$ & $64(65.3)$ & \\
\hline \multicolumn{4}{|c|}{ Substance abuse by an intimate partner } \\
\hline None & $144(73.8)$ & $89(90.8)$ & 0.01 \\
\hline Alcohol only & $32(16.4)$ & $7(7.1)$ & \\
\hline $\begin{array}{l}\text { Illicit drugs (eg, marijuana) } \\
\text { only }\end{array}$ & $10(5.1)$ & $1(1.0)$ & \\
\hline $\begin{array}{l}\text { Both alcohol and illicit } \\
\text { drugs }\end{array}$ & $9(4.6)$ & $1(1.0)$ & \\
\hline \multicolumn{4}{|l|}{ Infant birth outcomes } \\
\hline $\begin{array}{l}\text { Gestational age at delivery } \\
\text { in weeks (Q1-Q3) }\end{array}$ & $38-41$ & $39-42$ & \\
\hline $\begin{array}{l}\text { Median birth weight in } \\
\text { grams (IQR) }\end{array}$ & $3000(500)$ & $3100(600)$ & \\
\hline Low birth weight $(<2500 \mathrm{~g})$ & $15(7.7)$ & $0(0.0)$ & \\
\hline
\end{tabular}

*Total across categories may not add because of missing observations. Discrete variables were compared using $\mathrm{X}^{2}$ and Fisher's exact tests, while the continuous variables were compared with analysis of variance. Q1-Q3 is first quartile (Q1) to third quartile (Q3). IQR=Q3-Q1.

with the unexposed (48\%). Prevalence of substance abuse by an intimate partner was higher among the IPV exposed (26\%) than the unexposed women $(9.2 \%)$. Gestational age at delivery was lower in the IPV exposed
Table 2 Prevalence of exposure to different forms of prenatal intimate partner violence (IPV) among 293 term births

\begin{tabular}{|c|c|c|}
\hline Forms of exposure to IPV & $\begin{array}{l}\text { Number } \\
\text { (n) }\end{array}$ & $\begin{array}{l}\text { Prevalence } \\
(\%)\end{array}$ \\
\hline No IPV exposure during pregnancy & 98 & 33.4 \\
\hline $\begin{array}{l}\text { At least one form of IPV during } \\
\text { pregnancy }\end{array}$ & 195 & 66.6 \\
\hline $\begin{array}{l}\text { All three forms of IPV (combined } \\
\text { IPV) }\end{array}$ & 31 & 10.6 \\
\hline Any form of emotional IPV & 150 & 51.2 \\
\hline Emotional IPV only & 44 & 15 \\
\hline $\begin{array}{l}\text { Emotional IPV combined with } \\
\text { physical IPV }\end{array}$ & 53 & 18.1 \\
\hline $\begin{array}{l}\text { Emotional IPV combined with } \\
\text { sexual IPV }\end{array}$ & 22 & 7.5 \\
\hline Any form of physical IPV & 100 & 34.1 \\
\hline Physical IPV only & 8 & 2.7 \\
\hline $\begin{array}{l}\text { Emotional IPV combined with } \\
\text { physical IPV }\end{array}$ & 53 & 18.1 \\
\hline $\begin{array}{l}\text { Physical IPV combined with } \\
\text { sexual IPV }\end{array}$ & 8 & 2.7 \\
\hline Any form of sexual IPV & 90 & 30.7 \\
\hline Sexual IPV only & 29 & 9.9 \\
\hline $\begin{array}{l}\text { Emotional IPV combined with } \\
\text { sexual IPV }\end{array}$ & 22 & 7.5 \\
\hline $\begin{array}{l}\text { Physical IPV combined with } \\
\text { sexual IPV }\end{array}$ & 8 & 2.7 \\
\hline
\end{tabular}

compared with unexposed. Birth weight in the infants of the IPV exposed (median=3000 g; IQR=500) was lower than in infants of unexposed mothers $(3100 \mathrm{~g}$; $\mathrm{IQR}=600)$. Although we did not collect information about place of delivery, in the parent study from which all the participants came, few women $(2.3 \%)$ gave birth at home. ${ }^{31}$

\section{Prevalence of exposure to different forms of prenatal IPV among term births}

We observed that $67 \%$ of the mothers experienced at least one form of IPV during pregnancy and $11 \%$ were exposed to all three (table 2). A relatively small proportion of the IPV-exposed women were exclusively exposed to only one form of IPV. The prevalence of being exposed during pregnancy to emotional IPV, either alone or in combination with other forms of IPV was $51 \%$. Comparable prevalences were $34 \%$ for physical IPV and $31 \%$ for sexual IPV. The prevalence was $18 \%$ for the combination of emotional and physical violence, $8 \%$ for the combination of emotional and sexual violence, and $3 \%$ for physical and sexual violence.

\section{Factors associated with IPV during pregnancy among term} births

The characteristics associated with the emotional and physical forms of IPV were similar (online supplemental 
Table 3 Association of prenatal intimate partner violence (IPV) exposure, compared with no exposure, and birth weight (BW) as a continuous variable among 293 term births

\begin{tabular}{lrlll}
\hline IPV exposure & $\mathbf{N}$ & Mean BW (SD) grams & Crude model: $\beta^{*}, 95 \% \mathbf{C l}$ & Adjusted model: $\beta^{*}, 95 \%$ Cl \\
\hline No exposure to IPV & 98 & $3098(319)$ & Reference & Reference \\
Any form of IPV & 195 & $2995(442)$ & $-103(-201$ to -4$)$ & $-99(-201$ to 2$)$ \\
Any form of emotional IPV & 150 & $2987(459)$ & $-111(-215$ to -6$)$ & $-94(-202$ to 15$)$ \\
Any form of physical IPV & 100 & $2920(390)$ & $-178(-278$ to -78$)$ & $-162(-267$ to -58$)$ \\
Any form of sexual IPV & 90 & $2962(408)$ & $-136(-241$ to -31$)$ & $-139(-248$ to -30$)$ \\
Any two forms of IPV† & 83 & $2957(410)$ & $-240(-377$ to -103$)$ & $-145(-258$ to -32$)$ \\
All three forms of IPV & 31 & $2858(387)$ & $-223(-368$ to -77$)$ \\
\hline
\end{tabular}

The reference group for comparison in all analysis is no exposure to IPV.

${ }^{*}$ Difference in BW (in grams) for exposure to a form of IPV relative to no exposure. Adjusted for maternal age, parity, education and household poverty level.

†Any two forms of IPV=emotional and physical IPV, emotional and sexual IPV or physical and sexual IPV.

table S2). The factors associated with emotional and physical violence included intermediate or high poverty probability level, mothers without tertiary education, multiparity, substance abuse by an intimate partner and an intimate partner with less than tertiary education. Exposure to sexual violence did not vary across levels of most factors examined but women with no tertiary education had an elevated prevalence.

\section{Association between IPV during pregnancy with birth weight among term births}

Online supplemental table S3 shows the mean birth weight for the original categories of IPV exposure, recorded on the CTS, with $p$ values for the crude difference in birth weight for each category relative to no IPV of any kind. The mean birth weight of term births declines proportionally with increasing levels of exposure to different forms of prenatal IPV from none, once, twice, 3-5 times, 6-10 times, 11-20 times and >20 times. To address sparse data, categories of frequency of exposure were collapsed into three: no exposure to any type of IPV, one to five times or more than five times during the pregnancy for subsequent analyses. Prenatal exposure to each type or combination of types of IPV, compared with no exposure to any IPV, was associated with a reduction in birth weight among term newborns (table 3). Compared with newborns of mothers with no exposure to any type of IPV during pregnancy, birth weight was lower by $162 \mathrm{~g}$ (95\% CI -267 to -58$)$ for those exposed to physical IPV, $94 \mathrm{~g}(95 \% \mathrm{CI}-202$ to 15$)$ lower for exposure to emotional IPV and $139 \mathrm{~g}$ (95\% CI -248 to -30) lower for exposure to sexual IPV. The combination of all three forms of violence was associated with $223 \mathrm{~g}$ (95\% CI -368 to -77$)$ lower birth weight.

For each of the three types of violence, the reduction in birth weight increased across categories and the test for ordinal trend was significant (table 4). For emotional IPV, the association was strongest among the most highly exposed; women exposed more than five times had newborns with a birth weight of $155 \mathrm{~g}$ (95\% CI -277 to
-33) less than mothers unexposed to any form of IPV. For physical IPV the association with birth weight increased across categories; compared with unexposed women, those exposed one to five times had infants weighing $112 \mathrm{~g}$ (95\% CI -219 to -4$)$ less and those exposed more than five times had birth weight $380 \mathrm{~g}$ (95\% CI -553 to -206$)$ lower. Likewise for sexual violence, the reduction in birth weight was greatest at the highest exposure; mothers exposed more than five times had infants weighing $262 \mathrm{~g}$ (95\% CI -401 to -123$)$ less than women unexposed to any form of violence.

Among the Tanzanian term newborns, exposure to emotional violence was associated with birth weight $54 \mathrm{~g}$ (95\% CI -118 to 10$)$ lower than those unexposed to any form of IPV (online supplemental table S4). Compared with those unexposed, exposure to physical violence was associated $135 \mathrm{~g}(95 \% \mathrm{CI}-255$ to -15$)$ lower birth weight and sexual violence with $88 \mathrm{~g}(95 \% \mathrm{CI}-164$ to -11$)$ lower birth weight.

\section{DISCUSSION}

In this study of term births in Nigeria, we found that more than half of the mothers were exposed to at least one form of IPV during pregnancy and that this exposure was associated with reduced birth weight. The combination of two or all three forms of IPV had a slightly greater effect on birth weight than exposure to any one form of violence. Physical IPV alone was uncommon but in combination with other forms, it had the largest impact on birth weight. These findings were replicated in a similar population in Tanzania. In our study population we also observed a dose-response relationship between the number of instances of prenatal exposure to violence and reduced birth weight, with the strongest association for increasing exposure to physical violence.

The prevalence of IPV during pregnancy observed in our study is consistent with studies from Nigeria and sub-Saharan Africa in general. ${ }^{1325}$ We observed a higher 
Table 4 Association of the frequency of prenatal intimate partner violence (IPV) exposure and birth weight (BW) as a continuous variable among 293 term births

\begin{tabular}{|c|c|c|c|c|c|}
\hline IPV Exposure & $\mathbf{N}$ & $\begin{array}{l}\text { Mean BW (SD) } \\
\text { grams }\end{array}$ & Crude model: $\beta^{\star}, 95 \% \mathrm{Cl}$ & Adjusted model: $\beta^{\star}, 95 \% \mathrm{Cl}$ & $\begin{array}{l}\mathbf{P} \text { trend } \\
\text { ordinal }\end{array}$ \\
\hline No exposure to IPV & 98 & 3098 (319) & Reference & Reference & \\
\hline $1-5$ times & 60 & 3152 (319) & 54 (-74 to 182$)$ & $50(-80$ to 179$)$ & $<0.01$ \\
\hline$>5$ times & 135 & 2926 (409) & $-172(-276$ to -68$)$ & $-172(-279$ to -64$)$ & \\
\hline$>5$ times & 87 & 2925 (412) & $-173(-291$ to -55$)$ & $-155(-277$ to -33$)$ & \\
\hline \multicolumn{6}{|c|}{ Any form of physical IPV } \\
\hline $1-5$ times & 79 & $2978(367)$ & $-119(-223$ to -16$)$ & $-112(-219$ to -4$)$ & $<0.01$ \\
\hline$>5$ times & 21 & $2700(402)$ & $-398(-563$ to -233$)$ & $-380(-553$ to -206$)$ & \\
\hline
\end{tabular}

Categories of IPV frequency ( $0=$ none, $1=1-5$ times and $2=>5$ times during pregnancy). The reference group for comparison in all analysis is no exposure to IPV.

*Difference in BW (in grams) per category of IPV exposure relative to no exposure. Adjusted for maternal age, parity, education and household poverty level.

prevalence of violence in our study area than that reported in the Nigerian Demographic and Health Survey (NDHS 2018). ${ }^{37}$ This disparity could be attributed to different methodological approaches. Although the NDHS used the same tool for assessing IPV, we interviewed women postnatally in a secure setting that ensured their privacy, while eligible women in the NDHS were interviewed within the household, which can affect reporting rates for IPV. ${ }^{37}$ Indeed, a study analysing DHS survey data on IPV during pregnancy from 19 countries emphasised that the figures presented are likely to be underestimated because women may not have felt comfortable disclosing experiences of violence during pregnancy. ${ }^{38}$ Misreporting of sensitive topics may be common if respondents self-edit the information they report to avoid embarrassing themselves in the presence of an interviewer or to avoid repercussions from third parties. ${ }^{39} 40$

We found that exposure to any form of violence was associated with reduced birth weight. This association could be mediated by both biological and behavioural effects of IPV. ${ }^{41}$ Prenatal IPV is a stressor that provokes high levels of cortisol, which has been associated with a reduction in birth weight. ${ }^{10}$ Low social resources and maternal stress have also been associated with elevated cortisol levels. ${ }^{10}$ Our findings indicate that the association between IPV and birth weight is not strongly confounded by maternal age, parity, education or socioeconomic status. Although we did not collect information on smoking, our analysis of the Tanzanian study, which did assess this exposure, decreases the concern that our results are confounded by smoking.
According to the traditional interpretation of a biological gradient, the presence of a dose-response relationship supports a causal association between exposure and outcome. ${ }^{42}$ Some studies have reported that exposure to more instances or combinations of two or all three forms of IPV during pregnancy are more strongly related to risk of LBW as a binary variable. ${ }^{127}$ In our study of continuous birth weight among term infants, we found that exposure to more than one form of IPV was related to larger reduction in birth weight. Furthermore, our results showed a dose-response relationship between the number of instances of exposure to all types of IPV and birth weight. The association was strongest when physical IPV was included. The estimated effect of physical IPV on birth weight is similar in magnitude to that of maternal smoking during pregnancy, illustrating the importance of studying and implementing methods to reduce prenatal IPV. $^{34} 4344$

\section{Strengths and limitations}

The manner in which we calculated gestational age using months based on maternal report after birth is a limitation because of misclassification from imprecise reporting. We expect this misclassification to be non-differential with respect to IPV exposure but we have no data to evaluate this issue. The difficulty of enrolling women delivering at home is a major challenge to getting a representative sample of participants for perinatal research in Nigeria. ${ }^{31}$ We recognise the potential bias in birth weight measurement within 48 hours for infants born at home, as it is known that there is a $5 \%-10 \%$ loss of birth weight during the initial few days of life. ${ }^{45} 46$ However, the proportion 
of mothers that gave birth at home was too low to influence the mean birth weight and further we have reported that breastfeeding practices are comparable with those of women who delivered in the health facility. ${ }^{31}$ There could be unmeasured confounding for factors we did not assess, especially hypertension during pregnancy and pregnancy-associated malaria. However, we had a relatively short period of recruitment, which should standardise the seasonal exposure to malaria. ${ }^{47}{ }^{48}$ Prenatal maternal smoking and alcohol intake are established risk factors for LBW, but we do not have data for these exposures that have been documented to be uncommon among pregnant women in this population. ${ }^{49}{ }^{50}$ However, we did not observe confounding by smoking in the Tanzanian data. There is also a risk of potential recall bias due to collection of IPV data postnatally. The validation of our results in the prospectively collected Tanzanian data provides reassurance on this issue. ${ }^{19}$

Our study has several strengths. Our sample size is modest, but it is large relative to some previous studies. ${ }^{1325}$ We replicated our findings using a larger dataset from a Tanzanian prospective cohort study which produced results similar in magnitude and direction. We used the CTS for measuring the prevalence and frequency of occurrence for distinct forms of IPV that also enabled the estimation of a dose-response relationship. The CTS was also used in the NDHS, which makes our findings reliable for regional, national and international comparisons. The conduct of our interviews in a secured setting assured the women of their privacy thereby augmenting the reliability and validity of sensitive data such as IPV. ${ }^{51}$

\section{Conclusion and implication of findings}

All forms of IPV were associated with reduction of birth weight in our study of term births in Nigeria. Studying birth weight as a continuous variable among term births enables evaluation of the effect of prenatal IPV exposure on shifting the birth weight distribution, independent of the effect of gestational age ${ }^{18}$ Greater reductions in birth weight were seen with greater levels of exposure to each type of violence. Our findings on the importance of IPV suggest that specific nutritional or lifestyle interventions to improve birth outcomes that ignore this key exposure will be less likely to be successful. It is possible that effects of IPV on birth weight could differ by timing of exposure during pregnancy or by biological factors such as advancing maternal age and parity, or infections like HIV and malaria. Hence, there is a need for further research using larger datasets that more precisely measure timing of exposure along with these and other co-exposures.

Our findings underscore the urgency of protecting women from IPV as part of interventions to improve the distribution of birth weights. Prenatal IPV is a modifiable exposure that could be targeted for prevention. ${ }^{6}$ However, screening for IPV is not currently included in the standard of care in Nigeria, nor are interventions to reduce IPV. Thus, more work in this direction is needed. Given the magnitude of the effect we observed and the high prevalence of exposure, IPV research should be a public health priority.

\section{Author affiliations}

${ }^{1}$ Epidemiology Branch, National Institute of Environmental Health Sciences, National Institutes of Health, Durham, North Carolina, USA

${ }^{2}$ Department of Epidemiology and Community Medicine, Federal University Lafia, Lafia, Nigeria

${ }^{3}$ Department of Community Medicine, Kaduna State University, Kaduna, Nigeria

${ }^{4}$ Department of Social Sciences, Kaduna Polytechnic, Kaduna, Nigeria

${ }^{5}$ Department of Sociology, Kaduna State University, Kaduna, Nigeria

${ }^{6} 5$ CSR Hub Limited, Dhaka, Bangladesh

${ }^{7}$ Westat, Durham, North Carolina, USA

Contributors MAK, HS, HEY, QEH and SJL proposed and planned the study and analysis. MAK and HS provided the data. ASMM contributed to the interpretation of the Poverty Probability Index. MAK and MR-B analysed the data. MAK wrote the first draft of the manuscript. SJL supervised the development of the manuscript and reviewed the analytical approaches and interpretation of the results. All authors interpreted the data, critically revised drafts of the manuscript and approved the final manuscript.

Funding MAK, QEH and SJL are supported by the Intramural Research Program of the National Institutes of Health (NIH), National Institute of Environmental Health Sciences, Z01 ES 49019. Epidemiological Resources and Investigation Consultancy (ERIC) Limited and Perinatal Epidemiological Research Unit (Kaduna, Nigeria) provided infrastructure, human resource, and logistics for data collection and management.

Competing interests None declared.

Patient consent for publication Not required.

Ethics approval The study complies with Helsinki Declaration, national legislation and recommendations for proper conduct on research about intimate partner violence. Institutional Review Board approval was obtained from the Health Research Ethics Committee of the Ministry of Health and Human Services, Kaduna State, Nigeria (MOH/ADM/744/NOL/584). All the participants provided written informed consent by thumb printing. Participants were assured that the study was anonymous, and their privacy and confidentiality protected by the removal of identifying information during all the stages of data management, analysis and dissemination. Study data were collected and managed using Research Electronic Data Capture (REDCap) tools hosted at Perinatal Epidemiological Research Unit, Kaduna, Nigeria.

Provenance and peer review Not commissioned; externally peer reviewed.

Data availability statement The datasets generated and/or analysed during the study are not publicly available but are available from the first author or the corresponding author on request.

Supplemental material This content has been supplied by the author(s). It has not been vetted by BMJ Publishing Group Limited (BMJ) and may not have been peer-reviewed. Any opinions or recommendations discussed are solely those of the author(s) and are not endorsed by BMJ. BMJ disclaims all liability and responsibility arising from any reliance placed on the content. Where the content includes any translated material, BMJ does not warrant the accuracy and reliability of the translations (including but not limited to local regulations, clinical guidelines, terminology, drug names and drug dosages), and is not responsible for any error and/or omissions arising from translation and adaptation or otherwise.

Open access This is an open access article distributed in accordance with the Creative Commons Attribution Non Commercial (CC BY-NC 4.0) license, which permits others to distribute, remix, adapt, build upon this work non-commercially, and license their derivative works on different terms, provided the original work is properly cited, appropriate credit is given, any changes made indicated, and the use is non-commercial. See: http://creativecommons.org/licenses/by-nc/4.0/.

ORCID iD

Musa Abubakar Kana http://orcid.org/0000-0002-5766-7610

\section{REFERENCES}

1 Donovan BM, Spracklen CN, Schweizer ML, et al. Intimate partner violence during pregnancy and the risk for adverse 
infant outcomes: a systematic review and meta-analysis. BJOG 2016;123:1289-99.

2 Hill A, Pallitto C, McCleary-Sills J, et al. A systematic review and meta-analysis of intimate partner violence during pregnancy and selected birth outcomes. Int J Gynaecol Obstet 2016;133:269-76.

3 Halim N, Beard J, Mesic A, et al. Intimate partner violence during pregnancy and perinatal mental disorders in low and lower middle income countries: a systematic review of literature, 1990-2017. Clin Psychol Rev 2018;66:117-35.

4 Mendez-Figueroa H, Dahlke JD, Vrees RA, et al. Trauma in pregnancy: an updated systematic review. Am J Obstet Gynecol 2013;209:1-10.

5 Garcia-Moreno CJH, Ellsberg M, Heise L, et al. WHO multi-country study on women's health and domestic violence against women: initial results on prevalence, health outcomes and women's responses. Geneva: World Health Organization, 2005.

6 Capaldi DM, Knoble NB, Shortt JW, et al. A systematic review of risk factors for intimate partner violence. Partner Abuse 2012;3:231-80.

7 Bayrampour $\mathrm{H}$, Vinturache $\mathrm{A}$, Hetherington $\mathrm{E}$, et al. Risk factors for antenatal anxiety: a systematic review of the literature. J Reprod Infant Psychol 2018;36:476-503.

8 Woldetensay YK, Belachew T, Biesalski HK, et al. The role of nutrition, intimate partner violence and social support in prenatal depressive symptoms in rural Ethiopia: community based birth cohort study. BMC Pregnancy Childbirth 2018;18:374.

9 Jamieson B. Exposure to interpersonal violence during pregnancy and its association with women's prenatal care utilization: a metaanalytic review. Trauma Violence Abuse 2020;21:904-21.

10 Valladares E, Peña R, Ellsberg M, et al. Neuroendocrine response to violence during pregnancy--impact on duration of pregnancy and fetal growth. Acta Obstet Gynecol Scand 2009;88:818-23.

11 Murphy CC, Schei B, Myhr TL, et al. Abuse: a risk factor for low birth weight? A systematic review and meta-analysis. CMAJ 2001;164:1567-72.

12 Nesari M, Olson JK, Vandermeer B, et al. Does a maternal history of abuse before pregnancy affect pregnancy outcomes? A systematic review with meta-analysis. BMC Pregnancy Childbirth 2018;18:404

13 Shamu S, Abrahams N, Temmerman M, et al. A systematic review of African studies on intimate partner violence against pregnant women: prevalence and risk factors. PLoS One 2011;6:e17591.

14 Reichenheim ME, Moraes CL. Comparison between the abuse assessment screen and the revised conflict tactics scales for measuring physical violence during pregnancy. $J$ Epidemiol Community Health 2004;58:523-7.

15 Straus MA. Cross-cultural reliability and validity of the revised conflict tactics scales: a study of university student dating couples in 17 nations. Cross-Cultural Res 2004;38:407-32.

16 Doi S, Fujiwara T, Isumi A. Development of the intimate partner violence during pregnancy instrument (IPVPI). Front Public Health 2019;7:43

17 Wilcox AJ, Skjaerven R. Birth weight and perinatal mortality: the effect of gestational age. Am J Public Health 1992;82:378-82.

18 Wilcox AJ. On the importance--and the unimportance--of birthweight. Int J Epidemiol 2001;30:1233-41.

19 Sigalla GN, Mushi D, Meyrowitsch DW, et al. Intimate partner violence during pregnancy and its association with preterm birth and low birth weight in Tanzania: a prospective cohort study. PLoS One 2017;12:e0172540-e.

20 Koen N, Wyatt GE, Williams JK, et al. Intimate partner violence: associations with low infant birthweight in a South African birth cohort. Metab Brain Dis 2014;29:281-99.

21 Berhanie E, Gebregziabher D, Berihu H, et al. Intimate partner violence during pregnancy and adverse birth outcomes: a casecontrol study. Reprod Health 2019;16:22.

22 Pool MS, Otupiri E, Owusu-Dabo E, et al. Physical violence during pregnancy and pregnancy outcomes in Ghana. BMC Pregnancy Childbirth 2014;14:71.

23 Kaye DK, Mirembe FM, Bantebya G, et al. Domestic violence during pregnancy and risk of low birthweight and maternal complications: a prospective cohort study at Mulago Hospital, Uganda. Trop Med Int Health 2006;11:1576-84.

24 Eno EE, Fawole AA, Aboyeji AP, et al. Domestic violence and obstetric outcome among pregnant women in llorin, North central Nigeria. Int J Gynaecol Obstet 2014;125:170-1.

25 Orpin J, Papadopoulos C, Puthussery S. The prevalence of domestic violence among pregnant women in Nigeria: a systematic review. Trauma Violence Abuse 2020;21:3-15.
26 Ameh N, Shittu So, Abdul MA. Obstetric outcome in pregnant women subjected to domestic violence. Niger J Clin Pract 2009;12:179-81.

27 Coker AL, Sanderson M, Dong B. Partner violence during pregnancy and risk of adverse pregnancy outcomes. Paediatr Perinat Epidemiol 2004;18:260-9.

28 Fawole AO, Hunyinbo KI, Fawole OI. Prevalence of violence against pregnant women in Abeokuta, Nigeria. Aust N Z J Obstet Gynaecol 2008:48:405-14.

29 Lee ACC, Katz J, Blencowe $\mathrm{H}$, et al. National and regional estimates of term and preterm babies born small for gestational age in 138 lowincome and middle-income countries in 2010. Lancet Glob Health 2013;1:e26-36.

30 Review of World Population. Population of cities in Nigeria, 2019. Available: $\mathrm{http}: / /$ worldpopulationreview.com/countries/nigeriapopulation/cities/

31 Kana MA, Ahmed J, Ashiru AY, et al. Child electronic growth monitoring system: an innovative and sustainable approach for establishing the Kaduna infant development (KID) study in Nigeria. Paediatr Perinat Epidemiol 2020;34:532-43.

32 Straus MA. Measuring intrafamily conflict and violence: the conflict tactics (CT) scales. Physical violence in American families. Routledge, 2017: 29-48.

33 Straus MA, Hamby SL, Boney-McCoy SUE, et al. The revised conflict tactics scales (CTS2): development and preliminary psychometric data. J Fam Issue 1996;17:283-316.

34 Kramer MS. Determinants of low birth weight: methodological assessment and meta-analysis. Bull World Health Organ 1987;65:663.

35 Shah PS, Knowledge Synthesis Group on Determinants of LBW/PT births. Parity and low birth weight and preterm birth: a systematic review and meta-analyses. Acta Obstet Gynecol Scand 2010;89:862-75.

36 Schreiner M. Simple poverty scorecard poverty assessment tool: Nigeria, 2015. Available: http://www.simplepovertyscorecard.com/ NGA_2012_ENG.pdf [Accessed 20 Apr 2019].

37 National Population Commision (Nigeria). Nigeria demographic and health survey 2013. National population Commission and ORC macro. Rockville, Maryland, USA, 2014

38 Devries KM, Kishor S, Johnson $\mathrm{H}$, et al. Intimate partner violence during pregnancy: analysis of prevalence data from 19 countries. Reprod Health Matters 2010;18:158-70.

39 Tourangeau R, Yan T. Sensitive questions in surveys. Psychol Bull 2007;133:859-83.

40 Krumpal I. Determinants of social desirability bias in sensitive surveys: a literature review. Qual Quant 2013;47:2025-47.

41 Bailey B. Partner violence during pregnancy: prevalence, effects, screening, and management. Int $J$ Womens Health 2010;2:183-97.

42 Rothman KJ, Greenland S. Causation and causal inference in epidemiology. Am J Public Health 2005;95:S144-50.

43 Werler MM. Teratogen update: smoking and reproductive outcomes. Teratology 1997;55:382-8.

44 Difranza JR, Lew RA. Effect of maternal cigarette smoking on pregnancy complications and sudden infant death syndrome. J Fam Pract 1995;40:117.

45 Wright CM, Parkinson KN. Postnatal weight loss in term infants: what is normal and do growth charts allow for it? Arch Dis Child Fetal Neonatal Ed 2004;89:F254-7.

46 Marchini G, Stock S. Thirst and vasopressin secretion counteract dehydration in newborn infants. J Pediatr 1997;130:736-9.

47 Patel JC, Hathaway NJ, Parobek CM, et al. Increased risk of low birth weight in women with placental malaria associated with P. falciparum VAR2CSA clade. Sci Rep 2017;7:7768.

48 Igboeli NU, Adibe MO, Ukwe CV, et al. Prevalence of low birth weight before and after policy change to IPTp-SP in two selected hospitals in southern Nigeria: eleven-year retrospective analyses. Biomed Res Int 2018;2018:4658106

49 Caleyachetty R, Tait CA, Kengne AP, et al. Tobacco use in pregnant women: analysis of data from demographic and health surveys from 54 low-income and middle-income countries. Lancet Glob Health 2014;2:e513-20.

50 Envuladu E, Agbo H, Ashikeni M, et al. Determinants of substance abuse among pregnant women attending ANC in a tertiary hospital in Jos plateau state Nigeria. Int J Public Health Res 2013;1:1-5.

51 Garcia-Moreno C, Watts C, Heise L, et al. Putting women first: ethical and safety recommendations for research on domestic violence against women. Geneva: WHO, 2001. 